\title{
Human Breast Cancer Cell Lines as Models of Growth Regulation and Disease Progression
}

\author{
Stephen P. Ethier ${ }^{1}$
}

\begin{abstract}
The routine isolation and culture of human breast cancer cells from patient samples has been a goal of breast cancer cell biologists for over 30 years. Despite extensive work in this area and the development of many human breast cancer cell lines, the proportion of patient samples that give rise to immortalized breast cancer cell lines is still disappointingly low. The majority of human breast cancer cell lines that have been established were isolated many years ago and have been grown continuously under poorly defined culture conditions. These cell lines have been useful for studies of the estrogen receptor biology in human breast cancer cells, in identifying growth factors synthesized by breast cancer cells, and for the characterization of genetic alterations in oncogenes and tumor suppressor genes present in these cells. More recently, tissue culture methods have improved, resulting in the ability to culture routinely normal human mammary epithelial cells of specific lineages and this has resulted in the development of new human breast cancer cell lines. The ability to isolate and culture normal and neoplastic human mammary epithelial cells under similar culture conditions has improved these models dramatically and has resulted in the identification of altered cellular phenotypes of human breast cancer cells.
\end{abstract}

KEY WORDS: Breast cancer cell lines; estrogen receptors; growth factors; oncogenes; tumor suppressor genes.

\section{INTRODUCTION}

Over 20 years ago, Herbert Soule opened his paper describing the isolation of the MCF-7 human breast cancer cell line with the statement, "Attempts to cultivate long-term differentiated epithelial cell cultures from human breast tumors have met with only limited success." He went on to describe difficulties with fibroblast overgrowth, death of cancer cells in primary culture, and failure of the tumor cells to divide after subculture, all of which limited the isolation and establishment of human breast cancer cell lines (1). Unfortunately, one could write strikingly similar words today, as many of the same problems discussed by Soule and others have not been completely resolved.

\footnotetext{
'Department of Radiation Oncology, Division of Cancer and Radiation Biology, University of Michigan Medical School, Ann Arbor, Michigan 48109-0582. e-mail: spethier@umich.edu.
}

Despite the relative lack of success with the development of culture models involving primary human breast cancer $(\mathrm{HBC})^{2}$ cells, we have learned a great deal about human mammary epithelial cell biology and transformation using cell culture model systems that have been developed over the past 10 years. This has been largely the result of striking improvements in culture of normal human mammary epithelial (HME) cells that have led directly to improved model systems of HBC cell growth. However, progress in this area is still far from complete. In this review, the in vitro model systems for the study of human breast cancer cell biology developed and used since the isolation of the first human breast cancer cell lines will be

\footnotetext{
${ }^{2}$ Abbreviations: EGF, epidermal growth factor; ER, estrogen receptor; HBC, human breast cancer; HME, human mammary epithelial; $\mathrm{PgR}$, progesterone receptor; TGF- $\alpha$, transforming growth factor-alpha.
} 
Table I

\begin{tabular}{|c|c|c|}
\hline In vitro model system & Advantages & Disadvantages \\
\hline $\begin{array}{l}\text { Primary HME cell culture } \\
\text { systems }\end{array}$ & $\begin{array}{l}\text { Diploid mammary epithelial cells that grow } \\
\text { under well-defined conditions } \\
\text { Cells are serially subculturable } \\
\text { Cells can be transformed by transduction of } \\
\text { specific oncoproteins }\end{array}$ & $\begin{array}{l}\text { Difficult to obtain tissues and culture cells } \\
\text { Finite proliferative lifespan } \\
\text { Not all lineages grow in culture } \\
\text { Serum required for growth of keratin-19- } \\
\text { positive cells }\end{array}$ \\
\hline $\begin{array}{l}\text { Primary HBC cells and early- } \\
\text { passage cell lines; e.g., } 21 \mathrm{~T} \\
\text { cells, HMT3909S8, SUM- } \\
\text { 44PE, SUM-52PE, SUM- } \\
\text { 102PT, etc. }\end{array}$ & $\begin{array}{l}\text { Experiments can be performed with early- } \\
\text { passage cells that grow under well-defined } \\
\text { conditions } \\
\text { Growth kinetics and growth factor } \\
\text { requirements mimic the in vivo situation } \\
\text { Cell lines obtained from primary and } \\
\text { metastatic sites } \\
\text { Opportunity to discover new molecular changes } \\
\text { important in breast cancer } \\
\text { Opportunity to link genetic alterations and } \\
\text { altered growth phenotypes of breast cancer cells }\end{array}$ & $\begin{array}{l}\text { Very difficult to propagate the neoplastic cells } \\
\text { Overgrowth of normal HME cells } \\
\text { Overgrowth of fibroblasts in primary culture } \\
\text { Cells can be cultured from only about } 10 \% \\
\text { of specimens } \\
\text { Cells from many specimens undergo apoptosis } \\
\text { during the first few days of culture }\end{array}$ \\
\hline
\end{tabular}

discussed. The progress that has been made in our understanding of $\mathrm{HBC}$ cell biology using these systems will be reviewed and the various strengths and weaknesses of these model systems will be assessed (see Table I for a summary).

\section{ESTABLISHMENT OF HBC CELL LINES WITH UNDEFINED CULTURE MEDIA}

Before 1970, there had been only sporadic reports of cell lines isolated from human breast cancer specimens $(2,3)$. In 1973 the isolation of both the MCF-7 and $\mathrm{SkBr}-3$ cell lines was reported $(1,4)$. In 1974 Cailleau et al. (5) described an extensive attempt to systematically develop human breast cancer cell lines from pleural effusion metastases. These workers turned to pleural effusions as a source of human breast cancer cells after failing to develop a single human breast cancer cell line from over 200 primary tumors. They reasoned that pleural effusions might be a better source of cells than primary tumors since they often consist of large numbers of cancer cells that are relatively free of fibroblasts and because serial samples can sometimes be obtained from individual patients. The tissue culture methods used by Cailleau and co-workers were typical of the culture conditions used by most laboratories at that time. A basal medium such as Leibovitz' L-15 was used and supplemented with either $10 \%$ or $20 \%$ fetal bovine serum in the presence or absence of effusion fluid from the patient sample, and the cells were grown on glass dishes. In the course of their studies, these investigators observed that the breast cancer cells attached poorly to the glass surface, but the continued passage of free-floating cells led directly to the development of several of the MDA-MB cell lines. Despite their systematic approach, these workers succeeded in establishing cell lines from only about $10 \%$ of the pleural effusion specimens obtained. This success rate has not been significantly improved upon in the intervening 20 years.

The MCF-7 cell line developed by Soule and coworkers (1), isolated in much the same way as the MDA-MB lines, possessed two characteristics that made it a particularly exciting model for human breast cancer biology. First, the cells expressed estrogen receptors (ER) in vitro. These receptors were functional in that estrogen treatment resulted in up-regulation of progesterone receptor $(\mathrm{PgR}) \mathrm{mRNA}$ and protein (6). Second, inoculation of MCF-7 cells into immuno- 
deficient mice resulted in development of progressively growing tumors, but only if the animals were treated with estrogen pellets (7). Thus, the MCF-7 cell line became the first model of estrogen-dependent human breast cancer.

The discovery that MCF-7 cells are estrogendependent for growth in vivo led to many studies aimed at understanding the mechanisms by which estrogen promotes cell growth as well as the mechanisms by which breast cancer cells become estrogen-independent. A thorough review of the literature on this subject is beyond the scope of this review; however, a few major points can be addressed here. Most studies on the role of estrogen in MCF-7 growth focused on the question of whether the hormone acted as a direct mitogen or whether it promoted growth by an indirect mechanism. Support for the "indirect" hypothesis came from the observation that $\mathrm{MCF}-7$ cells do not have the same estrogen requirement for growth in vitro as they do in vivo. Indeed, these cells were shown to proliferate in serum-free medium and under these conditions have no requirement for or response to exogenous estrogens (8). Subsequently, it was discovered that phenol red, present in culture medium as a $\mathrm{pH}$ indicator, has weak estrogenic activity (9). It was suggested that the phenol red in the culture medium accounted for the lack of response of these cells to exogenous estrogen. Indeed, most investigators who study estrogen effects with MCF- 7 cells and other ER-positive human breast cancer cell lines now grow the cells in phenol red-free medium. Under these conditions a consistent response to exogenous estrogens can be detected, particularly when cells are cultured in the presence of charcoalstripped serum (10-14). Nevertheless, MCF-7 cells have the capacity for continuous proliferation in the absence of exogenous estrogen when cultured in phenol red-free medium in the presence of charcoalstripped serum. Thus, these cells are estrogen-responsive in vitro and estrogen-dependent for growth in vivo.

One hypothesis that emerged from these studies was that polypeptide growth factors synthesized by breast cancer cells in response to estrogen mediate the mitogenic effects of estrogen by an autocrine mechanism. A number of factors have been proposed to act as estromedins, including transforming growth factor$\alpha$, insulin-like growth factors-I and -II, and other less well-defined factors $(15,16)$ (reviewed in refs. 17 and 18). However, transfection of MCF-7 cells with various growth factor genes does not make them estrogenindependent for growth in vivo (19). While it is clear that the TGF- $\alpha$ gene is estrogen-responsive and is upregulated by exogenous estrogen $(13,14,20)$, the observation that most ER-positive human breast cancers do not express the EGF receptor, and are therefore unresponsive to TGF- $\alpha$, suggests strongly that this growth factor cannot directly mediate the growth promoting effects of estrogen in human breast cancer cells $(21-23)$.

More recent work indicating that estrogen stimulation induces genes that block programmed cell death in breast cancer cells point to an alternative mechanism of estrogen action in MCF-7 cells (24). Thus, it is possible that, in vivo, estrogen is necessary to prevent breast cancer cells from undergoing programmed cell death and this may account for the lack of tumor development in vivo in the absence of estrogen.

Clearly the development of the MCF-7 cell line and other ER-positive HBC cell lines has had a profound impact on our understanding of the role of estrogen in human mammary carcinogenesis. Despite the fact that our understanding of the role of estrogen in this process is incomplete, experiments using these model cell lines have provided valuable data in a number of areas. The cloning of the ER gene and the molecular analysis of this gene in human breast cancer cell lines has led to a new understanding of the function of the ER in various human breast cancer specimens. For example, it is now known that the estrogen receptor gene can undergo mutations and rearrangements that modify its ability to bind ligand, bind to DNA, and induce new gene transcription. This has helped to explain why some breast cancers are ER-positive yet do not respond to antiestrogen therapy, and why there is discordance in some breast cancer specimens between ER expression and PgR expression. Thus, some breast cancers are ER-negative, but PgR-positive. This unusual phenotype can result from an ER that does not bind ligand, but constitutively activates the PgR gene. Such tumors are unlikely to be responsive to antiestrogen therapy. Similarly, some breast cancer cells can express a dysfunctional ER that binds ligand, but does not activate gene transcription. These cells are clinically ER-positive, but functionally estrogen-independent for growth and will also be refractory to antiestrogen therapy $(25,26)$.

The isolation of ER-negative $\mathrm{HBC}$ cell lines has also yielded important discoveries. The family of growth factors now collectively known as the heregulins or neuregulins were originally discovered in conditioned medium of MDA-MB-231 cells (27-29). Other cell lines have been useful for studies of putative oncogenes and tumor suppressor genes such as the $\operatorname{erbB}$ 
family of protooncogenes and the p53 gene, and have improved our understanding of the role that these genes play in the malignant behavior of HBC cells (30).

As discussed above, MCF-7 and other cell lines in routine use today have enhanced our understanding of HBC biology. However, these model systems have significant drawbacks. First, the majority of the available HBC cell lines originated from late-stage metastatic specimens. Thus, studies of human breast cancer at the cellular and molecular level have been limited to the very latest stages of disease progression. We still know very little about the biology of $\mathrm{HBC}$ cells that constitute primary tumors. In addition, cell lines that are in routine use came from a small subset of metastatic samples, suggesting that we may be studying only the most aggressive subpopulations of breast cancer cells. Finally, with the exception of a small number of cell lines to be discussed subsequently, most $\mathrm{HBC}$ cell lines are routinely cultured under undefined conditions and have been serially passaged for many years. The lack of definition of culture conditions precludes an in-depth understanding of exogenous factors that regulate $\mathrm{HBC}$ cell proliferation. Furthermore, the fact that these cells undergo significant phenotypic changes with long-term passage adds another important caveat regarding these cells as models of human breast cancer cell proliferation. From our own experiences with establishing human breast cancer cell lines, it is clear that breast cancer cells continue to evolve in vitro and cells beyond passage 50 are phenotypically very different from early passage cells. There is no reason to believe that the changes that occur in vitro mimic the changes that occur in vivo, as the selection pressures are likely to be very different. Thus, one has to interpret with caution results obtained from experiments with high-passage human breast cancer cell lines.

\section{DEVELOPMENT OF IMPROVED CULTURE METHODS FOR NORMAL AND NEOPLASTIC HUMAN MAMMARY EPITHELIAL CELLS}

The modest success in developing good in vitro models of human breast cancer cell proliferation prompted several groups to take an alternative approach to this problem by developing culture systems for normal human mammary epithelial cells. The overriding assumption made by most investigators who took this experimental approach was that normal human mammary epithelial cells would be more diffi- cult to propagate in vitro than cancer cells. This entirely reasonable assumption turned out to be false and it is now quite clear that normal human mammary epithelial cells are much easier to grow in vitro than are breast cancer cells. Indeed, with current cell culture technology it is possible to culture normal mammary epithelial cells of both luminal and basal-myoepithelial lineages from virtually every patient sample.

Prior to 1980 there were only scattered reports of isolation and growth in vitro of normal HME cells and, in these cases, growth had been limited to a small number of cell doublings in primary culture (31-35). This field began to change dramatically with the work of Stampfer and co-workers (36). These workers first developed an undefined medium that supported growth and serial passage of relatively pure cultures of $\mathrm{HME}$ cells. This "MM" medium consisted of conditioned medium from several human mammary epithelial and myoepithelial cell lines, $5 \%$ fetal bovine serum, as well as insulin, epidermal growth factor, and hydrocortisone. The medium was later improved with the addition of cholera toxin and a fibroblast feeder layer, which then supported clonal growth of normal HME cells (37). The lack of definition of the culture medium was a disadvantage of this system and this problem was rectified by the development of a serum-free, conditioned medium-free culture medium that supported similar levels of normal HME cell growth. This medium, as reported by Hammond et al. (38), contained pituitary extract as its only undefined component. However, cells could be cloned and grown for a limited number of passages by replacing the pituitary extract with prostaglandin E1 and prolactin.

Soon after the development of this culture system, other laboratories developed similar culture systems. We developed a serum-free medium to support longterm growth of normal rat mammary epithelial cells and later showed that this medium supported extensive proliferation of normal HME cells as well (39-41). Our culture system differed from Stampfer's in several ways. First, we used Ham's F-12 as our basal medium as opposed to a 1:1 mix of DME and Ham's F-12 or MCDB 170. Additionally, HME cells were cultured on type I collagen-coated tissue culture dishes and our medium did not contain pituitary extract. This medium does contain bovine serum albumin, which represents an undefined component. Otherwise, the growth factor combinations that we employed were similar to those reported by Hammond et al. (38) and previously by Stampfer et al. (36). Other variations of this medium were reported by Petersen and van Deurs (42) and Band et al. $(43,44)$. Thus, by the late 1980 s several 
cell culture systems had been developed that could support long-term growth of normal HME cells.

Over the next several years, these culture model systems were used by many investigators to pursue two general directions: a renewed attempt to isolate and culture human breast cancer cells from patient samples and induction of neoplastic transformation of normal HME cells by exposing them to carcinogenic agents in vitro. There was, however, an important problem with these culture systems that had an impact on the interpretation of results obtained with these model systems. It was clear that all of the cell culture media described above supported growth of mammary cells of epithelial origin. The proliferating cells expressed desmosomes and microvilli and had keratins as their intermediate filaments. But it was not known whether these media supported proliferation of all the mammary epithelial cell types present in the gland or if there was selection for a specific cell type or lineage. Insight into this problem came from the demonstration that different epithelial cell types express different keratin isoforms, and the development of monoclonal antibodies capable of distinguishing these keratin isoforms. Using these tools, Taylor-Papadimitriou $e t$ al. (45) demonstrated that mammary epithelium in vivo consists of basal and luminal cells that differ in their pattern of keratin expression. Further, they demonstrated that human breast cancer arises from luminal cells and that breast cancer cells uniformly express cytokeratin 19 in vivo. Importantly, all established HBC cell lines also express keratin-19 in vitro. These investigators then convincingly showed that HME cells that proliferate in the Hammond-Stampfer medium and others like it are uniformly keratin-19-negative, suggesting that they are derived from a lineage different from breast cancer cells. The cells that do proliferate under these conditions may have stem-cell-like characteristics, as they are sometimes positive for keratins- 8 and -18 (also luminal cell keratins) and smooth muscle actin (a basal cell marker). Thus, although significant progress had been made in the development of in vitro models of normal HME cell growth, the inability to culture cells that express the same cytokeratins as breast cancer cells represented a significant problem.

\section{NEW ATTEMPTS AT ISOLATION OF HUMAN BREAST CANCER CELLS USING ENRICHED CULTURE MEDIA}

The development of culture systems and media that support long-term growth of normal HME cells prompted renewed attempts to isolate and culture human breast cancer cells from primary tumor specimens. Initially there was great optimism that these cell culture methods had provided a breakthrough, as several laboratories successfully cultured HME cells from primary breast cancers. Furthermore, cells cultured in this way sometimes exhibited phenotypic differences that appeared to distinguish them from HME cells derived from reduction mammoplasty specimens (41). However, cells isolated from breast cancers and cultured under these conditions exhibited other characteristics that suggested that they were not, in fact, breast cancer cells, but rather, normal HME cells that were present in the tumor specimen $(46-48)$. It was repeatedly found that cells cultured from tumor specimens did not give rise to immortalized cell lines, but rather lost proliferative capacity after several population doublings. Two possible explanations for this observation were that breast cancer cells are not immortalized, or that the culture media designed for growth of normal cells selected for normal HME cells present in the breast cancer specimens. Two subsequent observations demonstrated clearly that the latter hypothesis was correct. First, Wolman et al. (49) demonstrated that the cells that grew out of primary breast cancer specimens were uniformly diploid even when the cells of the uncultured tumor were aneuploid. Second, cytokeratin antibodies demonstrated that, like cells cultured from normal tissues, cells cultured from breast cancer specimens were uniformly keratin-19negative (45). Taken together, these results indicated that culture media that had been shown to stimulate rapid proliferation of normal HME cells from normal tissues also selected for the rapid growth of these cells from breast cancer specimens. This no doubt explains why cells cultured from breast cancer specimens did not express the immortalized phenotype.

The experiments described above prompted the initiation of experiments in our laboratory aimed at modifying culture conditions to selectively isolate and grow keratin-19-positive luminal cells in vitro. The underlying assumption for this work was that improvements in the culture of luminal HME cells would improve the frequency with which breast cancer cell lines could be isolated. We found that the simple addition of $5 \%$ fetal bovine serum to our enriched culture medium was sufficient to allow the emergence and continuous growth of luminal mammary epithelial cells that stained positively for keratin-19 (Fig. 1). Filter cloning techniques were used in conjunction with this medium to isolate and propagate pure cultures of keratin-19-positive HME cells. We then 

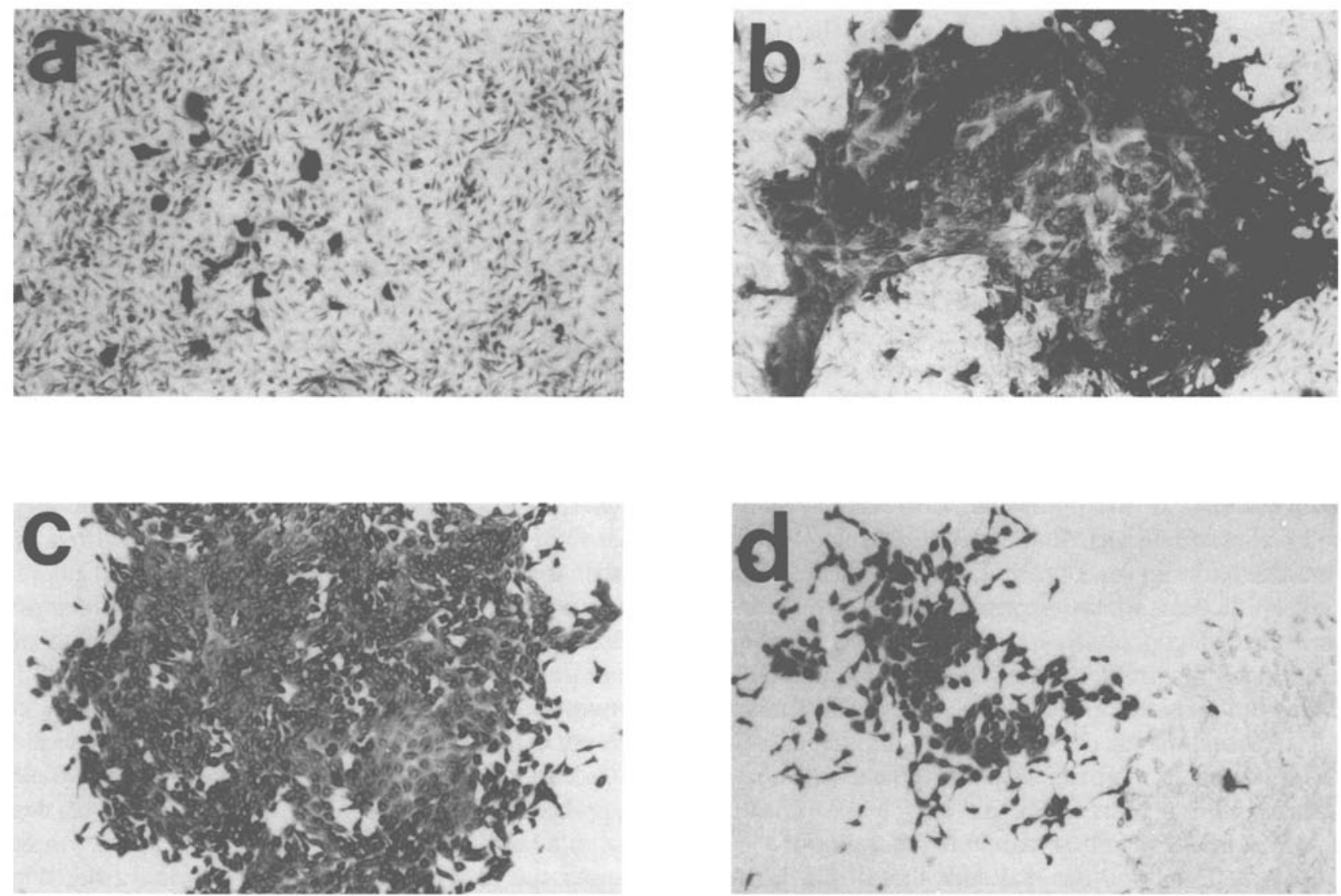

Fig. 1. Photomicrographs of human mammary epithelial cells cultured from normal and neoplastic tissues and immunostained with antibodies against keratin-19. (a) Keratin-19-negative, normal tissue-derived cells cultured in growth factor-supplemented serum-free medium; (b) parallel culture from the same specimen grown in growth factor- and serum-supplemented medium showing keratin-19positive colony; (c, d) primary breast cancer-derived cultures growing in serum- and growth factor-supplemented medium. Note keratin19-positive colony growing adjacent to a keratin-19-negative colony in panel d.

set out to use this medium to culture cells from primary human breast cancers or pleural effusion metastases. As with the normal tissues, this medium allowed routine isolation and serial propagation of keratin-19-positive HME cells from a very high proportion of human breast cancer specimens. However, as before, these cells uniformly had a finite proliferative lifespan in vitro. We then identified two primary tumor specimens with known genetic alterations: a p53 mutation in one and an erbB-2 amplification in the other. Keratin-19-positive colonies were isolated from these specimens and analyzed for the genetic alterations known to be present in the malignant cells. The cultured cells had normal p53 and erbB-2 genes, showing conclusively that they were derived from normal cells present in the specimen. Likewise, we were unable to isolate and culture human breast cancer cell lines from pleural effusion specimens using the medium that supports growth of normal luminal HME cells (50). These results indicate clearly that the growth requirements of human breast cancer cells in vitro are dramatically different from those of normal HME cells and that even highly malignant $\mathrm{HBC}$ cells do not proliferate in medium that supports growth of normal luminal HME cells.

\section{SUCCESSFUL ISOLATION OF HBC CELL LINES USING ENRICHED CULTURE MEDIA}

Despite the inability of the culture systems described above to yield consistent growth of HBC cells, three separate groups did report isolation of new human breast cancer cell lines using the kind of enriched culture media used to grow normal cells. 
Petersen et al. (51), using the culture medium developed in their laboratory, isolated a cell line designated HMT-3909S8. These cells were immortal, aneuploid, and expressed cytokeratins consistent with their origin from luminal mammary epithelial cells. Further, these cells were tumorigenic in nude mice. Despite this success, the authors were careful to point out that only this one cell line was obtained from a large number of biopsy specimens.

Similar results were reported by Band $e t$ al. (43, 52 ), who isolated a series of cell lines from serial biopsy specimens from an individual patient. Two cell lines originated from the primary tumor (21NT and 21PT lines) and one line originated from a pleural effusion metastasis. The latter cell line was subcloned based on morphological differences, yielding two distinct cell lines designated 21MT-1 and 21MT-2. The development of these cell lines from the same patient represents the first in vitro model of human breast cancer progression. These cell lines vary in their relative tumorigenicity in nude mice and in the expression of an amplified $e r b B-2$ gene in these cells. The progressive overexpression and activation of $e r b B-2$ in these cell lines correlates with their increasing aggressiveness in vivo and their progressive growth factor independence in vitro. $\mathrm{HBC}$ cell lines were not established from other patient-derived samples using an identical approach.

Meltzer et al. (53) also isolated two human breast cancer cell lines using an enriched medium. As above, the cell lines were obtained from attempts with a large number of biopsy specimens.

Taken together, the results of the work described above indicate that use of defined media can result in the isolation of human breast cancer cell lines from a subset of breast cancer specimens. This suggests that specific subsets of breast cancer cells proliferate under certain culture conditions. This hypothesis is supported by the following evidence. First, all three groups reported the isolation of only one or two cell lines from attempts with many patient samples. Second, the cellular and molecular characteristics of the cell lines have important similarities. For example, all three of the media employed by these groups contained epidermal growth factor (EGF) and all three cell lines derived from primary tumors were dependent on this factor for growth. Additionally, all of these cell lines have an amplification of the erbB-2 gene that is overexpressed in the cells. Thus, it seems likely that the culture media used by these groups select for a subset of human breast cancers with a particular set of molec- ular alterations. Clearly, erbB-2 amplification alone cannot account for this, since the frequency of cell line isolation is significantly lower than the frequency of $e r b B-2$ amplification in breast cancer. Therefore, this single molecular change may be necessary but insufficient to allow growth of HBC cells under growth factor-enriched culture conditions.

The evidence from work in our laboratory is also consistent with the hypothesis that the culture conditions used to isolate HBC cells determine the type of breast cancer cells that are isolated. In a series of experiments using pleural effusion-derived breast cancer cells, we found that omission of several "factors" present in the medium used to culture normal luminal HME cells significantly improved our ability to isolate and grow breast cancer cells. For example, we found that breast cancer cells derived from several patients lost viability when cultured on type I collagen-coated plates and when grown in the presence of cholera toxin. Both of these agents are strong positive enhancers of growth of normal HME cells. In fact, we found that a simplified culture medium consisting of Ham's F12 supplemented with $5 \%$ fetal bovine serum, insulin, and hydrocortisone resulted in the isolation of three immortalized cell lines, two from pleural effusion metastases $(50,54)$ and one from a primary tumor (manuscript in preparation). In addition, one long-term cell strain was isolated from a metastatic lymph node (55). Since this culture medium does not contain EGF, the cell lines so far isolated using this approach either have no requirement for exogenous EGF for proliferation or are unable to grow in the presence of EGF. The two pleural effusion-derived breast cancer cell lines (SUM-44PE and SUM-52PE) are both ER-positive and do not express the EGF receptor and thus have no EGF requirement for growth. The SUM-16LN cell line, isolated from a metastatic lymph node, had an amplification of the EGF receptor gene and dramatically overexpressed the receptor, which was constitutively tyrosine phosphorylated. Like most other human cancer cells with amplifications of the EGF receptor gene, these cells were potently growth-inhibited by exogenous EGF. The SUM-102PT cell line, derived from a primary tumor, does express EGF receptors and is EGF-responsive in culture, but can grow continuously in the absence of exogenous EGF (manuscript in preparation). Thus, using culture conditions that differ significantly from those described earlier, we have isolated human breast cancer cells from a distinctly different subset of patients. Specifically, none of the cell lines that we isolated have an EGF require- 
ment for in vitro growth and none of them have an amplified erbB-2 gene. This indicates that different subsets of breast cancers with different genetic alterations regulate proliferation in different ways. Thus, it seems unlikely that a single cell culture system can be used to isolate and culture breast cancer cells from all patients.

In addition to revealing more about the culture requirements for a different subset of human breast cancer cells, the experiments described above provided other insights concerning in vitro growth requirements of human breast cancer cells. First, it is clear from our studies as well as those of others that early-passage HBC cells proliferate in culture with kinetics similar to those in vivo $(42,50,51)$. Thus, these cells proliferate with population doubling times of $100-200 \mathrm{hr}$ or more. The kinetics of HBC cell proliferation that we and others have observed in vitro is completely consistent with kinetic measurements made in vivo (56-58). These slow proliferation rates are maintained for many passages in culture and this explains why the emergence of normal HME cells prevents the isolation of HBC cells when growth factor-enriched culture media are used. Normal cells respond exceptionally well to growth factor combinations present in the enriched media, resulting in their rapid proliferation and overgrowth.

A second factor that also distinguishes breast cancer cells from normal HME cells is the density dependence of $\mathrm{HBC}$ cells for in vitro growth. Whereas normal HME cells can grow at clonal density in growth factor-enriched media, HBC cells are highly sensitive to changes in cell density. Thus, in our hands, establishment of breast cancer cell lines has required initial plating of breast cancer cells at high density and maintaining that high density by propagating the cells at low split ratios. We have propagated our cell lines by subculturing at 1:3 split ratios every 2 weeks. Subculturing the cells at lower densities results in loss of the proliferative potential of the cells. Interestingly, this cell density dependence can be partially overcome by culturing the cells at low density in the presence of conditioned medium from high-density cultures of the same cells (unpublished observations).

\section{THE ROLE OF PROGRAMMED CELL DEATH IN VITRO IN ESTABLISHMENT OF HBC CELL LINES}

As can be seen from the above discussion, improvements in tissue culture methods have resulted in the isolation of several new human breast cancer cell lines that grow under well-defined conditions. However, the overall success rate for isolation of HBC cell lines has not dramatically improved in 20 years. The explanation for this phenomenon may lie in observations made by the early investigators in this field as well as in our own studies with a large number of breast cancer specimens $(1,5)$. In our hands, most breast cancer cells fail to proliferate in culture not because they are in a quiescent state, but rather because the cells die within 1 week to 1 month in culture. Preliminary evidence suggests that some HBC cells undergo apoptosis when seeded into tissue culture. This suggests that the cell culture milieu induces a signaling pathway leading to programmed cell death. Furthermore, this appears to be the case even with very aggressive metastatic HBC cells. We observed a startling example of this with a specimen in our laboratory designated SUM-133, derived from a malignant ascites specimen. SUM-133 cells are an aneuploid population that had an S-phase fraction in vivo of nearly 20\%. When these cells were placed in culture, they attached well and, at high density, formed nearly confluent patches on the dish. Within 1 week, however, the cells began to lose viability and by 1 month in culture the plate was essentially devoid of breast cancer cells. We have not been able to reverse this process by addition of exogenous growth factors. However, omission of hydrocortisone from the culture medium results in dramatically enhanced viability of the cells, slow proliferation, and response to growth factors that were ineffective in the presence of the glucocorticoid. This suggests that glucocorticoid-induced pathways leading to programmed cell death are activated in vitro, resulting in a change in phenotype of the cells from an aggressive, rapidly growing population to one that undergoes apoptosis. As we learn more about the various signaling pathways that induce programmed cell death we may obtain a more clear understanding of why HBC cells that proliferate in vivo lose viability when placed in tissue culture. A better understanding of this phenomenon may dramatically improve the success rate for isolation and culture of $\mathrm{HBC}$ cells and may have translational potential by suggesting novel ways to induce apoptosis in a highly malignant cell population.

\section{TRANSFORMATION OF HME CELLS IN VITRO}

As mentioned earlier, the development of culture systems that support extended proliferation of HME 
cells prompted attempts to transform these cells in vitro using carcinogenic agents. It should be pointed out that these in vitro transformation studies were carried out prior to 1989 , and thus before it was known that only nonluminal HME cells proliferated in culture.

One of the most striking results to come from the in vitro transformation experiments concerned the difficulty in inducing transformed phenotypes in these cells. Stampfer and Bartley (59) reported on the influence of benzo $(a)$ pyrene exposure on HME cells growing in culture and found that carcinogen treatment resulted in an extended lifespan of the HME cells, but only very rarely yielded an immortalized cell line. Indeed, the 184 cell line developed by these investigators was the only immortalized HME cell line to emerge from these experiments despite attempts with many HME specimens. In fact, it is striking that in the intervening time period, only two spontaneously immortalized HME cell lines have been established, indicating further how rare this transforming event is $(60,61)$. The 184 line developed by Bartley and Stampfer, though immortal, did not exhibit any other phenotypes of neoplastic cells, such as tumorigenicity in immunodeficient mice or growth under anchorageindependent conditions.

After the development of the 184 cell line, experiments were carried out aimed at inducing complete neoplastic transformation of these immortalized cells. Interestingly, neoplastic variants were never obtained from the 184 cells by further administration of chemical carcinogens. A variant of the 184 cell line was isolated by culturing the cells in selective medium, resulting in the establishment of a line designated 184A1N4. These cells were used in experiments aimed at transducing and expressing viral oncogenes in the cells in an attempt to induce complete neoplastic transformation. 184AlN4 cells transduced with SV-40 Tantigen or $\mathrm{v}-\mathrm{Ha}$-ras genes alone were either nontumorigenic in vivo or only weakly so. However, coexpression of both of these viral oncogenes resulted in cells that were highly tumorigenic in vivo (62). Thus, complete in vitro transformation of normal HME cells was successfully accomplished by the combined action of two potent viral oncogenes operating in a previously immortalized cell line. The relevance of these results to human breast carcinogenesis is unclear, in that the cells derived from the 184 cell line are not of the luminal lineage. Nevertheless, these studies emphasize the role of multiple genetic alterations in the complete neoplastic transformation of human cells.

\section{SUMMARY}

Over the past 30 years over two dozen human breast cancer cell lines have been isolated using different experimental approaches. Experiments performed with these cell lines have resulted in a massive literature that covers virtually every aspect of breast cancer biology. Despite these accomplishments, the fact that HBC cells can be isolated and cultured from only about $10 \%$ of both primary and metastatic specimens indicates in a clear way how much we still have to learn about the biology of HBC cells. What has become clear in recent years is that the factors that regulate proliferation of $\mathrm{HBC}$ cells in vitro are significantly different from those that control growth of normal HME cells. These findings have important implications for our understanding of the phenotypic effects of genetic changes that occur in known and still to be discovered oncogenes and tumor suppressor genes in HBC. For example, it is known that the MYC, ERBB2, PRAD-1, P53, BRCA-1, and RB genes are involved in human mammary carcinogenesis, but the phenotypic effects of these genetic changes are still poorly understood. Acquiring a thorough understanding of the phenotypic effects of the genetic alterations that occur during breast cancer progression will require the ability to isolate and study $\mathrm{HBC}$ cells in vitro on a routine basis. Thus, the continued development and improvement of in vitro model systems of $\mathrm{HBC}$ is critically important if we are to gain a thorough understanding of the biological consequences of oncogene and tumor suppressor gene changes that occur in the course of human mammary carcinogenesis.

\section{REFERENCES}

1. H. D. Soule, J. Vazques, A. Long, S. Albert, and M. Brennan (1973). A human cell line from a pleural effusion derived from a breast carcinoma. J. Natl. Cancer Inst. 51:1409-1416.

2. E. Y. Lasfargues and L. Ozzello (1958). Cultivation of human breast carcinomas. J. Natl. Cancer Inst. 21:1131-1147.

3. Y. V. Dobrynn (1963). Establishment and characteristics of cell strains from some epithelial tumors of human origin. J. Natl. Cancer Inst. 31:1173-1196.

4. G. Trempe and J. Fogh (1973). Variation in characteristics of human tumor cell lines derived from similar tumors. In Vitro 8:433

5. R. Cailleau, R. Young, M. Olive, and W. J. J. Reeves (1974). Breast tumor cell lines from pleural effusions. $J$. Natl. Cancer Inst. 53:661-666.

6. S. C. Brooks, E. R. Locke, and H. D. Soule (1973). Estrogen receptor in a human cell line (MCF-7) from breast carcinoma. J. Biol. Chem. 248:6251-6253.

7. H. D. Soule and C. M. McGrath (1980). Estrogen responsive proliferation of clonal human breast carcinoma cells in athymic mice. Cancer Lett. 10:177-189. 
8. D. Barnes and G. Sato (1979). Growth of a human mammary tumour cell line in a serum-free medium. Nature 281:388-389.

9. Y. Berthois, J. A. Katzenellenbogen, and B. S. Katzenellenbogen (1986). Phenol red in tissue culture media is a weak estrogen: Implications concerning the study of estrogen-responsive cells in culture. Proc. Natl. Acad. Sci. USA 83:2496-2500.

10. S. E. Pratt and M. N. Pollak (1993). Estrogen and antiestrogen modulation of MCF-7 human breast cancer cell proliferation is associated with specific alterations in accumulation of insulin-like growth factor-binding proteins in conditioned media. Cancer Res. 53:5193-5198.

11. A. Aakvaag, E. Utaaker, T. Thorsen, O. A. Lea, and H. Lahooti (1990). Growth control of human mammary cancer cells (MCF7 cells) in culture: Effect of estradiol and growth factors in serum-containing medium. Cancer Res. 50:7806-7810.

12. K. P. Karey and D. A. Sirbasku (1988). Differential responsiveness of human breast cancer cell lines MCF-7 and T47D to growth factors and 17B-estradiol. Cancer Res. 48:4083-4092.

13. R. B. Dickson, S. E. Bates, M. E. McMananway, and M. E. Lippman (1986). Characterization of estrogen responsive transforming activity in human breast cancer cell lines. Cancer Res. 46:1707-1713.

14. R. B. Dickson, K. K. Huff, E. M. Spencer, and M. E. Lippman (1985). Induction of epidermal growth factor related polypeptides by $17 \beta$-estradiol in MCF-7 human breast cancer cells. Endocrinology 118:138-142.

15. K. K. Huff, C. Knabbe, R. Lindsey, D. Kaufman, D. Bronzert, M. E. Lippman, and R. B. Dickson (1988). Multihormonal regulation of insulin-like growth factor I-related protein in MCF-7 human breast cancer cells. Mol. Endocrinol. 2:200-208.

16. K. K. Huff, D. Kaufman, G. H. Gabbay, E. M. Spencer, M. E. Lippman, and R. B. Dickson (1986). Secretion of an insulinlike growth factor-1-related protein by human breast cancer cells. Cancer Res. 46:4613-4619.

17. M. E. Lippman, R. B. Dickson, A. Kasid, E. Gelmann, N. Davidson, M. McManaway, K. Huff, D. Bronzert, S. Bates, S. Swain, and C. Knabbe (1986). Autocrine and paracrine growth regulation of human breast cancer. J. Steroid Biochem. 24:147-154.

18. M. E. Lippman, R. B. Dickson, E. P. Gelmann, N. Rosen, C. Knabbe, S. Bates, D. Bronzert, K. Huff, and A. Kasid (1987). Growth regulation of human breast carcinoma occurs through regulated growth factor secretion. J. Cell. Biochem. 35:1-16.

19. R. Clarke, N. Brunner, D. Katz, P. Glanz, R. B. Dickson, M. E. Lippman, and F. G. Kern (1989). The effects of constitutive expression of transforming growth factor-a on the growth of MCF-7 human breast cancer cells in vitro and in vivo. Mol. Endocrinol. 3:372-380.

20. S. E. Bates, N. E. Davidson, E. M. Valverius, C. E. Freter, R. B. Dickson, J. P. Tam, J. E. Kudlow, M. E. Lippman, and D. S. Salomon (1988). Expression of transforming growth factoralpha and its messenger ribonucleic acid in human breast cancer: Its regulation by estrogen and its possible functional significance. Mol. Endocrinol. 2:543-555.

21. S. Nicholson, P. Halcrow, J. R. Farndon, J. R. C. Sainsbury, P. Chambers, and A. L. Harris (1989). Expression of epidermal growth factor receptors associated with lack of response to endocrine therapy in recurrent breast cancer. Lancet. 8631:182-185.

22. S. Nicholson, J. Richard, C. Sainsbury, P. Halcrow, P. Kelly, B. Angus, C. Wright, J. Henry, J. R. Farndon, and A. L. Harris (1991). Epidermal growth factor receptor (EGFr)-Results of a six year follow-up study in operable Breast cancer with emphasis on the node negative subgroup. $B r . J$. Cancer 63:146-150.

23. A. L. Harris, S. Nicholson, J. R. C. Sainsbury, J. Farndon, and C. Wright (1989). Epidermal growth factor receptors in breast cancer: Association with early relapse and death, poor response to hormones and interactions with neu. J. Steroid Biochem. 34:123-131.

24. M. Kyprianou, H. F. English, N. E. Davidson, and J. T. Isaacs (1991). Programmed cell death during regression of the MCF7 human breast cancer following estrogen ablation. Cancer Res. 51:162-166.

25. S. A. W. Fuqua, S. D. Fitzgerald, G. C. Chamness, A, K. Tandon, D. P. McDonnell, Z. Nawaz, B. W. O'Malley, and W. L. Mcguire (1991). Variant human breast tumor estrogen receptor with constitutive transcriptional activity. Cancer Res. 51:105-109.

26. S. A. W. Fuqua, G. C. Chamness, and W. L. Mcguire (1993). Estrogen receptor mutations in breast cancer. J. Cell Biochem. 51:135-139.

27. W. E. Holmes, M. X. Sliwkowski, R. W. Akita, W. J. Henzel, L. J., J. W. Park, D. Yansura, N. Abadi, H. Raab, G. D. Lewis, M. Shepard, W.-J. Kuang, W. I. Wood, D. V. Goeddel, and R. L. Vandlen (1992). Identification of heregulin, a specific activator of p185erb2. Science 256:1205-1210.

28. R. Lupu, R. Colomer, B. Kannan, and M. E. Lippman (1992). Characterization of a growth factor that binds exclusively to the erbB-2 receptor and induces cellular responses. Proc. Natl. Acad. Sci. USA 89:2287-2291.

29. R. Lupu, R. Colomer, G. Zugmaier, J. Sarup, M. Shepard, D. Slamon, and M. E. Lippman (1990). Direct interaction of a ligand for the erbB2 oncogene product with the EGF receptor and pl85erbB2. Science 249:1552-1555.

30. M. H. Kraus, J. H. Pierce, T. P. Fleming, K. C. Robbins, P. P. DiFiore, and S. A. Aaronson (1988). Mechanisms by which genes encoding growth factors and growth factor receptors contribute to malignant transformation. In Membrane in Cancer Cells, New York Academy of Sciences, New York.

31. J. Taylor-Papadimitriou, M. Shearer, and M. G. P. Stoker (1977). Growth requirements of human mammary epithelial cells in culture. Int. J. Cancer 20:903-908.

32. R. C. Hallowes, R. Millis, D. Pigott, M. Shearer, M. G. P. Stoker, and J. Taylor-Papadimitriou (1977). Results on a pilot study of cultures of human lacteal secretions and benign and malignant breast tumors. Clin. Oncol. 3:81-90.

33. E. V. Gaffney, F. P. Polanowski, S. E. Blackburn, J. T. Lambiase, and R. E. Burke (1976). Cultures of normal human mammary cells. Cell Differ. 5:69-81.

34. E. V. Gaffney and D. Pigott (1978). Hydrocortisone stimulation of human mammary epithelial cells. In Vitro 14:621-624.

35. J. Taylor-Papadimitriou, M. Shearer, and R. Tilly (1977). Some properties of cells cultured from early-lactation human milk. J. Natl. Cancer Inst. 58:1563-1571.

36. M. Stampfer, R. C. Hallowes, and A. J. Hackett (1980). Growth of normal human mammary cells in culture. In Vitro 16:415-425.

37. H. S. Smith, S. Lan, R. Ceriani, A. J. Hackett, and M. R. Stampfer (1981). Clonal proliferation of cultured nonmalignant and malignant human breast epithelia. Cancer Res. 41:4637-4643.

38. S. L. Hammond, R. G. Ham, and M. R. Stampfer (1984), Serum-free growth of human mammary epithelial cells: Rapid clonal growth in defined medium and extended serial passage with pituitary extract. Proc. Natl. Acad. Sci. USA $81: 5435-5439$

39. S. P. Ethier (1985). Primary culture and serial passage of normal and carcinogen-treated rat mammary epithelial cells in vitro. J. Natl. Cancer Inst. 74:1307-1318.

40. S.P. Ethier (1986). Serum-free culture conditions for the growth of normal rat mammary epithelial cells in primary culture. In Vitro Cell. Dev. Biol. 22:485 490.

41. S. P. Ethier, R. M. Summerfelt, K. C. Cundiff, and B. B. Asch (1990). The influence of growth factors on the proliferative 
potential of normal and primary breast cancer-derived human breast epithelial cells. Breast Cancer Res. Treat. 17:221-230.

42. O. W. Petersen and B. van Deurs (1987). Preservation of defined phenotypic traits in short-term cultured human breast carcinoma derived epithelial cells. Cancer Res. 47:856-866.

43. V. Band and R. Sager (1989). Distinctive traits of normal and tumor derived human mammary epithelial cells expressed in a medium that supports long-term growth of both cell types. Proc. Natl. Acad. Sci. USA 86:1249-1253.

44. D. Zajchowski, V. Band, N. Pauzie, A. Tager, M. Stampfer, and R. Sager (1988). Expression of growth factors and oncogenes in normal and tumor-derived human mammary epithelial cells. Cancer Res. 48:7041-7047.

45. J. Taylor-Papadimitriou, M. Stampfer, J. Barter, A. Lewis, M. Boshell, E. B. Lane, and I. M. Leith (1989). Keratin expression in human mammary cells cultured from normal and malignant tissue: relation to in vivo phenotypes and influence of medium. J. Cell Sci. 94:403-413.

46. R. B. Owens, H. S. Smith, W. A. Nelson-Rees, and E. L. Springer (1976). Epithelial cell cultures from normal and cancerous tissues, J. Natl. Cancer Inst. 56:843-849.

47. H. S. Smith, A. J. Hacket, J. L. Riggs, M. W. Mosesson, J. R. Walton, and M. R. Stampfer (1979). Properties of epithelial cells cultured from human carcinomas and non-malignant tissues. J. Supramol. Struct. 11:147-166.

48. M. R. Stampfer, A. J. Hacket, H. S. Smith, M. C. Hancock, J. P. Leung, and T. S. Edgington (1982). Growth of human mammary epithelium in culture and expression of tumor-specific properties. In Growth-Cells in Hormonally Defined Media, Cold Spring Harbor, Laboratory, Cold Spring Harbor, New York.

49. S. R. Wolman, H. S. Smith, M. Stampfer, and A. J. Hackett (1985). Growth of diploid cells from breast cancers. Cancer Genet. Cytogenet. 16:49-64.

50. S. P. Ethier, M. L. Mahacek, W. J. Gullick, T. J. Frank, and B. L. Weber (1993). Differential isolation of normal luminal mammary epithelial cells and breast cancer cells from primary and metastatic sites using selective media. Cancer Res. 53:627-635.

51. O. W. Petersen, B. van Deurs, K. V. Nielsen, M. W. Madsen, I. Laursen, I. Balslev, and P. Briand (1990). Differential tumorigenicity of two autologous human breast carcinoma cell lines, HMT-3909S1 and HMT-3909S8, established in serum-free medium. Cancer Res. 50:1257-1270.
52. V. Band, D. Zajchowski, D. Swisshelm, D. Trask, V. Kulesa, C. Cohen, J. Connolly, and R. Sager (1990). Tumor progression in four mammary epithelial cell lines derived from the same patient. Cancer Res. 50:7351-7357.

53. P. Meltzer, A. Leibovitz, W. Dalton, H. Villar, T. Kute, J. Davis, R. Nagle, and J. Trent (1991). Establishment of two new cell lines derived from human breast carcinomas with $H E R-2 / n e u$ amplification. Br. J. Cancer 63:727-735.

54. K. E. Kokeny, C. A. Dilts, and S. E. Ethier (1994). Erb-B family receptor expression and growth regulation in two newly isolated human breast cancer cell lines. Breast Cancer Res. Treat. (submitted).

55. M. L. Mahacek, D. G. Beer, T. S. Frank, and S. P. Ethier (1993). Finite proliferative lifespan in vitro of a human breast cancer cell strain isolated from a metastatic lymph node. Breast Cancer Rest. Treat. 28:267-276.

56. V. Collins, R. K. Loeffler, and H. Tivey (1956). Observations on growth rates of human tumors. Am. J. Roentgenol. 76:988-1000

57. J. Gershon-Cohen, S. M. Berger, and H. S. Klickstein (1963), Roentgenography of breast cancer moderating concept of biological predeterminism. Cancer 16:961-964.

58. D. V. Fournier, E. Weber, W. Hoeffken, et al. (1980). Growth rate of 147 mammary carcinomas. Cancer 45:2198-2207.

59. M. R. Stampfer and J. C. Bartley (1985). Induction of transformation and continuous cell lines from normal human mammary epithelial cells after exposure to benzo[a]pyrene. Proc. Natl. Acad. Sci. USA 82:2394-2398.

60. H. D. Soule, T. M. Malony, S. R. Wolman, W. D. Peterson, R. Brenz, C. M. McGrath, J. Russo, R. J. Pauley, R. F. Jones, and S. C. Brooks (1990). Isolation and characterization of a spontaneously immortalized human breast epithelial cell line, MCF-10. Cancer Res. 50:6075-6086.

61. M. W. Madsen, A. E. Lykkesfeldt, I. Laursen, K. V. Nielsen, and P. Briand (1992). Altered gene expression of c-myc, epidermal growth factor receptor, transforming growth factor-a, and c$e r b-B 2$ in an immortalized human breast epithelial cell line, HMT-3522, is associated with decreased growth factor requirements. Cancer Res. 52:1210-1217.

62. R. Clark, M. R. Stampfer, R. Milley, E. O'Rourke, K. H Walen, M. Kriegler, J. Kopplin, and F. McCormick (1988). Transformation of human mammary epithelial cells by oncogenic retroviruses. Cancer Res. 48:4689-4694. 